\title{
Stiff Heart and Stiff Arteries. Could We Soften Both?
}

\author{
Vasilios G. Athyros ${ }^{1, *}$, Konstantinos Tziomalos $^{2}$, Michael A. Farganis ${ }^{1}$ and Paraschos Geleris ${ }^{3}$
}

\author{
${ }^{1}$ Second Propedeutic Department of Internal Medicine, Medical School, Aristotle University of Thessaloniki, Hippokra- \\ tion Hospital, Thessaloniki, Greece; ${ }^{2}$ First Propedeutic Department of Internal Medicine, Medical School, Aristotle \\ University of Thessaloniki, AHEPA Hospital, Thessaloniki, Greece; ${ }^{3}$ Third Cardiology Department, Medical School, \\ Aristotle University of Thessaloniki, Hippokration Hospital, Thessaloniki, Greece
}

\begin{abstract}
Old age, female gender, hypertension (HTN), cardiac ischaemia, and arterial stiffness (AS) are the main determinants of a stiff heart, diastolic dysfunction (DD), and finally heart failure with preserved ejection fraction (HFpEF); however, several cardiac or extra-cardiac pathologies may also be involved. The combined ventricular-arterial stiffening (abnormal left ventricle-arterial coupling) is the main determinant of the increased prevalence of HFpEF in elderly persons, particularly women, and in younger subjects with HTN. Hospitalization and mortality rates in patients with HFpEF are similar to those of patients with heart failure with reduced EF (HFrEF). However, although the prognosis of HFrEF has improved over time, the optimal treatment of HFpEF remains unclear, because of the differences in the pathophysiology of the two syndromes. A number of new drugs have shown promise but they will not be commercially available for several years. For the time being, aggressive treatment of non-cardiac comorbidities is the only option available for the management of HFpEF. Treatment of anaemia, sleep disorders, chronic kidney disease, non-alcoholic fatty liver disease, atrial fibrillation, diabetes mellitus, and judicious use of diuretics are effective to some degree. Statin treatment deserves special attention, regardless of the presence of dyslipidaemia, because it has been shown, mainly in small studies, post hoc analyses, and in a large recent meta-analysis, that it is related to an improved quality of life and a reduction in HF-related mortality. We urgently need to utilize these recourses to relieve a substantial number of patients suffering from $\mathrm{HFpEF}$, a disease with an ominous prognosis.
\end{abstract}

Keywords: Heart stiffness, arterial stiffness, diastolic dysfunction, ventricular arterial coupling, heart failure with preserved ejection fraction, hypertension, statins.

\section{INTRODUCTION}

Heart stiffness or diastolic dysfunction (DD) or heart failure with preserved ejection fraction (HFpEF) is characterised by abnormalities of ventricular filling, including decreased diastolic distensibility and impaired relaxation [1]. DD represents an important pathophysiological intermediate between hypertension (HTN) and heart failure (HF), and finally leads to HFpEF [2]. Up to $50 \%$ of patients with a history of HTN have evidence of DD [3], which represents an attractive target for HF prevention. However, no specific treatments have been definitively shown to improve DD to date [4]. During the last 20 years, HFpEF has turned into a serious health problem, accounting for practically half (40$71 \%$ ) of the cases of HF [1-3] and affecting $11-35 \%$ of the general population, with most patients having a subclinical form of the disease [4].

The most common causes of HFpEF are old age, HTN, and cardiac ischaemia but other diseases can also lead to HFpEF [5]. Heart stiffening and decreased filling result in decreased ability of the heart to pump blood to the body [6].

*Address correspondence to this author at the Second Propedeutic Department of Internal Medicine, Medical School, Aristotle University of Thessaloniki, Hippokration Hospital, Thessaloniki, Greece, 15 Marmara St, Thessaloniki, 55132, Greece;

Tel: +30 2310 892606; Fax: +30 2310835955 ;

Emails: athyros@med.auth.gr and vathyros@gmail.com
Moreover, elevated filling pressure in the ventricles can result in both pulmonary and peripheral oedema [4]. The arteries were considered by the ancient Greeks as motionless conduits within which air flowed; later it was described that the blood circulates through them. At present, it has been established that when the heart contracts it generates a blood wave that travels through the arteries. The speed of the travel of this wave is called pulse wave velocity (PWV) and is related to the stiffness or compliance of the arteries [7-11]. Arterial stiffness (AS) is characterized by increased PWV and early return to the ascending aorta of reflected waves, during the systolic phase of the pressure waveform, increasing systolic blood pressure (BP); reflected waves in healthy people return during diastole and contribute to myocardial perfusion. Thus, central systolic aortic blood pressure (CABP), and consequently left ventricular (LV) afterload, is increased. This culminates in LV hypertrophy (and stiffness) and predisposes to LV systolic and diastolic dysfunction [7]. Furthermore, in patients with AS, CABP during the diastole is decreased, thus substantially reducing coronary artery perfusion [7].

The relationship between AS and PWV was first reported in1808. Typical values of PWV in the aorta range from approximately 5 to $>15 \mathrm{~m} / \mathrm{s}$ [7]. Increased aortic PWV has been shown to predict cardiovascular disease (CVD)-related and all cause mortality in patients with end stage renal failure (ESRD), HTN and diabetes mellitus (DM) as well as in 
the general population [7-9]. Commercially available devices measure AS parameters, including the augmentation index (AIx) and PWV. These devices include the Complior, CVProfilor, PeriScope, Hanbyul Meditech, Mobil-O-Graph NG, Pulsecor, PulsePen and SphygmoCor. Heart is the primary site of damage caused by increased AS. Both arterial and LV stiffening may contribute to the transition from asymptomatic HF to overt HFpEF [7-10]. The functional interaction between the LV and arterial tree, termed ventriculararterial coupling, is recognized as a key determinant of cardiovascular performance [10-14]. This arterio-myocardial coupling decline is further precipitated by the presence of other CVD risk factors leading to the development of HFpEF $[5,14,15]$.

While tight BP control is a central component of HF prevention [16], the mechanisms by which $B P$ control decreases HF risk are not yet fully clear. The extent to which antihypertensive therapy reverses arterial and LV stiffness, or affects ventricular-arterial coupling and LV energetic efficiency, is not yet well understood [17]. Thus, there is no widely accepted treatment for $\mathrm{HFpEF}$ with proven clinical benefit [9-14].

\section{DIAGNOSIS OF HFPEF}

According to recent ESC guidelines [18], HFpEF is diagnosed when 4 criteria are met: symptoms of HF, clinical signs of HF, preserved LVEF ( $>50$, while EF $40-50 \%$ is in the grey zone) without LV dilatation and finally the existence of morphologic features (LV hypertrophy, left atrial dilatation) or functional characteristics indicating diastolic dysfunction and increased filling pressures [18]. In regard to diastolic function indices that should be carefully assessed, an increased ratio of transmitral inflow E wave to average E' of mitral annulus $\left(E / e^{\prime}\right)>15$ and a reduced average E' wave of mitral annulus measured by Tissue Doppler imaging $(<9$ $\mathrm{cm} / \mathrm{sec}$ ) both indicate elevated filling pressures [18].

\section{TREATMENT OPTIONS}

It has been proposed that HFpEF and HFrEF are part of the same HF continuum [19]. However, therapies with indisputable benefit in HFrEF have failed to show benefit in HFpEF [20,21], suggesting significant differences in the pathophysiology of these two entities. In the absence of proven treatments for $\mathrm{HFpEF}$, it is important to understand potential differences in response to empiric HF therapies [22].

The aim of the treatment of HFpEF should be to relieve symptoms and prolong life [4]. Unfortunately, to date, studies of neuro-hormonal blockade in patients with HFpEF have failed to show a decline in mortality rates or a clear improvement in quality of life [4]. Although inhibitors of the renin-angiotensin-aldosterone system (RAAS) and sympathetic nervous system should continue to be used in the population of patients with HFpEF who have other comorbidities such as HTN, DM or CVD, the use of these drugs for the primary treatment of HFpEF is not supported from current evidence [4]. In contrast to HFrEF patients, who mainly die from CVD, the increased mortality in HFpEF is driven mainly by non-CVD causes [23]. The main causes of death among HFpEF patients are sudden cardiac death, HF, myo- cardial infarction, stroke and non-CVD causes [24]. Thus, it is possible to improve quality of life and increase survival in HFpEF patients by aggressive treatment of co-morbidities [25].

\subsection{Lifestyle Measures}

A recent pilot study in 14 hypertensive patients with HFpEF suggested that a sodium-restricted diet improves several key factors that contribute to heart failure [26]. The Dietary Approaches to Stop Hypertension diet (DASH) reduced office systolic BP (from 155 to $138 \mathrm{mmHg}$ ) and 24hour systolic BP (130 to $123 \mathrm{mmHg}$ ) (both $\mathrm{P}=0.02$ ) at 3 weeks and also induced a non-significant drop in central end-systolic BP (116 to $111 \mathrm{mmHg}, \mathrm{P}=0.12$ ) [26]. Ventricular stiffness and relaxation indices improved, a trend toward lower energy for filling suggested increased diastolic efficiency, global contractility increased, effective arterial elastance decreased and ventricular-arterial coupling improved [26]. The findings of this short-term dietary intervention pilot study require confirmation in larger studies, but it is intriguing that large vessel AS, global LV contractility and ventricular-arterial coupling all significantly improved following DASH sodium-restricted diet in this cohort of elderly, obese patients [26]. Thus, salt restriction might prove a valuable tool in the management of HFpEF, although this has to be validated in larger long-term trials.

\subsection{Pharmacotherapy}

It has been suggested that besides the careful use of diuretics to improve symptoms there are no agents that improve the outcome of patients with HFpEF $[27,28]$. It has also been proposed that spironolactone could improve the prognosis of HFpEF. However, in the recently published Aldosterone Receptor Blockade in Diastolic HF (Aldo-DHF) trial, which included 422 patients with chronic HF, left ventricular (LV) ejection fraction of $>50 \%$, and echocardiographic evidence of LV DD, long-term aldosterone receptor blockade improved LV diastolic function but had no effect on maximal exercise capacity, HF symptoms, HF-related hospitalizations or quality of life [29].

A number of factors, including sex, body size, and age, are known to influence ventricular-arterial properties [3033]. It is not entirely clear how these factors may influence the ventricular-arterial response to antihypertensive therapy [34]. This was evaluated in a combined analysis $(n=527)$ of the Valsartan in Diastolic Dysfunction (VALIDD) [35] and Exforge Intensive Control of Hypertension to Evaluate Efficacy in Diastolic Dysfunction (EXCEED) studies [36]. It was shown that angiotensin receptor blockers (ARB) reduce arterial and ventricular stiffness, improve ventricular-arterial coupling, reduce cardiac work and improve LV efficiency and systolic and diastolic function [36]. Interestingly, sex and body weight were important determinants of the change in the coupling ratio and of the improvement in cardiac efficiency; women and obese patients achieved smaller reductions in the coupling ratio and smaller improvements in cardiac efficiency than men and non-obese individuals. This suboptimal response in women (even after adjusting for age, body weight and change in systolic BP) and in obese men suggest that structural and functional changes may be less 
reversible in these groups, possibly explaining their greater risk for HF [34]. Notably, the ratio of women to men affected by HFpEF is 2:1 [37] and obesity is also a major risk factor for HFpEF [38]. This combined analysis did not evaluate HF-related symptoms and did not have the power to assess survival.

\subsection{Pharmacological Agents Under Development}

Several drugs are in the pipeline, mainly in phase 2 and some in phase 3 studies, but they will not be commercially available for several years [39-57]. Detailed analysis of these agents is beyond the scope of the present review.

\subsection{Management of Comorbidities of Patients with HFpEF}

A promising strategy for the improvement of outcomes in patients with $\mathrm{HFpEF}$ is the aggressive treatment of noncardiac comorbidities $[18,58,59]$. Indeed, an important aspect of ventricular-arterial coupling is the detrimental impact of AS on LV diastolic function in different populations: in patients with chronic obstructive pulmonary disease (COPD), HTN, DM, ESRD, obstructive sleep apnea (OSA), liver dysfunction, anaemia, thyroid disorders and depression, which are all associated with increased morbidity and mortality [60]. Most of these noncardiac comorbidities share 2 common features: they may lead to LV dysfunction/HF [60,61] and they are associated with systemic inflammation $[60,62]$. The noncardiac comorbidity burden is higher in HFpEF patients than in those with HFrEF [63]. Therefore, aggressive management of comorbidities might result in larger benefits in HFpEF than in HFrEF [60]. The treatment of most of these comorbidities also has a beneficial effect on AS [64]. Accordingly, it appears that subcutaneous erythropoietin administration for anaemia might improve symptoms and survival in HFpEF patients with anaemia [65]. Tighter BP control (with judicious use of diuretics) may also reduce HFrelated events [66]. The Hypertension In the Very Elderly Trial (HYVET) study regarding the treatment of HTN in patients $>80$ years of age $(n=3,845)$ provided evidence that antihypertensive treatment with indapamide with or without perindopril was beneficial [67]. There was a reduction in the incidence of stroke (by 30\%, p = 0.05), all cause mortality (by $21 \%, p=0.02$ ), CVD mortality (by $23 \%, p=0.06$ ), CVD events (by 34\%, p = 0.001) and HF (by 64\%, p = 0.001). [67].

Improvement of renal function with atorvastatin [68] and resolution of NAFLD with atorvastatin and rosuvastatin [6974] are useful in the overall multifactorial approach of HFpEF [75] as well as of AS [76]. It appears that the above benefits are specific to these statins at appropriate doses and not a drug class effect.

Moreover, treatment of sleep-related disorders of breathing also appears to be beneficial in patients with HFpEF. Adaptive servoventilation (ASV) effectively attenuated nocturnal Cheyne-Stokes respiration (CSR) in patients with $\mathrm{HFpEF}$ and improved HF symptoms and cardiac function [77].

At an early stage, diabetic cardiomyopathy is manifested as $\mathrm{HFpEF}$, which is detected in up to $75 \%$ of asymptomatic diabetic patients [78]. In several patients, HFpEF may progress to HFrEF, with a poor prognosis (annual mortality rate of $15-20 \%$ ) [79]. Diabetic patients carry a 4- to 5-fold increased risk of HF [79]. In multivariable models, treatment with antidiabetic drugs, especially metformin, was associated with significantly lower risks of death or rehospitalization [79]. In contrast, thiazolidinediones should not be used in diabetic patients with established HF [80]. A reduction in deaths or hospitalizations was observed with metformin monotherapy vs sulfonylurea monotherapy [81], suggesting that metformin is both safe [82] and useful in HF $[81,82]$. The recently developed incretin-based therapies, such as glucagon-like peptide agonists and dipeptidyl peptidase-4 inhibitors, significantly improve cardiac function, including LV ejection fraction, and end-diastolic LV pressure, suggesting that they may represent a novel approach for the treatment of patients with T2DM-associated HF [83].

In a recent large trial in a national cohort of veterans with $\mathrm{HF}$, the burden of 15 noncardiac comorbidities and their impact on hospitalization and mortality were compared between patients with HFpEF and those with HFrEF [25]. The cohort consisted of 2,843 patients with HFpEF and 6,599 with HFrEF followed-up for 2 years. Compared with patients with HFrEF, those with HFpEF were older and had higher prevalence of COPD, DM, HTN, anaemia, obesity, peptic ulcer disease and cancer but a lower prevalence of chronic kidney disease (CKD). Comorbidities had similar impact on mortality in patients with HFpEF compared with those with HFrEF, except for COPD, which was associated with a greater risk in patients with HFpEF [25]. These data showed that there is a higher noncardiac comorbidity burden associated with higher non-HF hospitalizations in patients with HFpEF compared with those with HFrEF. This suggests that aggressive management of comorbidities may have a greater effect on HFpEF [25].

\subsection{Emerging Treatments}

It is probable that chronic low-grade inflammation of the myocardium and arterial wall plays an important role in the pathogenesis of both HFpEF and AS, since it has been repeatedly associated with increased risk for clinically manifest $\mathrm{HF}$ in large cohort studies [60]. Impaired diastolic function is thought to be due to concentric remodelling of the heart along with increased stiffness of both the extracellular matrix and myofilaments [49]. In addition, oxidative stress and low-grade inflammation are thought to have a role in HFpEF progression, along with endothelial dysfunction and impaired nitric oxide(NO)-cyclic guanosine monophosphateprotein kinase $\mathrm{G}(\mathrm{PKG})$ signalling [49]. The pathogenesis of AS that usually co-exists with HFpEF is also similar is and is another key factor of the worsening of HF symptoms $[84,85]$. Statins may attenuate most if not all these adverse pathogenetic factors through their pleitropic effects [86,87].

A recent meta-analysis of 15 prospective studies $(n=45,110)$ addressed the effects of statins in patients with HF [88]. The study included patients with both preserved and reduced EF and showed a reduction in all-cause mortality in patients treated with statins (risk ratio (RR) $0.71,95 \%$ confidence interval (CI) $0.61-0.83$ ) and a reduction in rehospitalization rate for HF (RR 0.84, 95\% CI 0.74-0.96) [88]. 
Statin treatment, however, had little impact on pump failurerelated mortality, CVD mortality and sudden cardiac death. Atorvastatin treatment appeared to reduce all-cause mortality ( RR 0.61, $\mathrm{P}=0.05$ ) and rehospitalization for HF (RR 0.44, $\mathrm{P}=0.04$ ) compared with non-atorvastatin statin therapy [88]. Thus, the statistical heterogeneity in the two outcomes could be partially accounted for by differences in the specific statin used [88].

A 2-year study reported the effect of statin treatment in $137 \mathrm{HFpEF}$ patients in comparison to angiotensin converting enzyme inhibitor (ACE-I) or ARB, beta-blocker, or calcium channel blocker [89]. The latter treatments had no significant effect on survival; in contrast, treatment with a statin was associated with a substantial improvement in survival, independent of other predictors for death and differences in baseline clinical features [hazard ratio (HR) 0.20 , 95\% CI 0.06 0.62] [89]. After propensity matching, statin therapy was associated with both improved survival and a trend for fewer CVD-related hospitalizations [89].

Statin therapy was evaluated in another small study in 146 patients with HFpEF. Patients were assigned to statin therapy $(n=103)$ or not $(n=43)$ and were followed for 1 year [90]. Statin therapy was independently associated with reduced all-cause mortality $(\mathrm{HR}=0.24,95 \%$ CI $0.07-0.90$, $\mathrm{p}<0.05)$ and $\mathrm{CV}$ rehospitalization rate $(\mathrm{HR}=0.55,95 \% \mathrm{CI}$ 0.33-0.92 $\mathrm{p}<0.05)$ [90]. In another long-term study [91], 270 patients with HFpEF were followed for over 5 years. Patients on statins demonstrated improved survival compared to patients not on statins ( $\mathrm{HR}=0.65,95 \%$ CI 0.45 $0.95, p=0.029)$ [91]. Thus, statin therapy appears to be associated with improved survival in patients with HFpEF during mid- and long-term follow-up [91].

The results of the small studies described above suggest that statins may improve mortality in patients with HFpEF. Whether these findings are generalizable to a broader group of patients with HFpEF remains unclear. This was evaluated in a nationwide sample of 61,939 Medicare recipients $\geq 65$ years of age who were hospitalized with a primary discharge diagnosis of HF [92]. From 54,960 patients finally included, only $16.7 \%$ received statins at discharge [92]. In a Cox proportional hazards model, discharge statin therapy was associated with significant improvements in 1- and 3-year mortality (HR 0.80, 95\% CI $0.76-0.84$ and HR, 0.82; 95\% CI, $0.79-0.85$, respectively). These results were independent from total cholesterol levels or presence of established CVD [92].

Statins also reduce AS in patients with dyslipidaemia [93-97], patients with or without CVD [98,99], postmenopausal women [100], patients with CKD [101], overweight and obese [102], patients with T2DM [103] or T1DM [104], healthy men [105], patients with rheumatoid arthritis [106] and elderly patients with HTN [107]. This effect of statins on AS is probably not a drug class effect, as suggested by the fact that the compound and the dose plays a significant role in the degree of AS reduction [98-107]. It seems that potent statins, such as atorvastatin and rosuvastatin, are more effective in reducing $\mathrm{AS}$ and consequently reducing excessive CVD risk [108]. This improvement in AS is probably one of the mechanisms through which statins improve HFpEF.
Recently, a new HFpEF paradigm has been proposed, with emphasis shifting from LV afterload excess to coronary microvascular inflammation [109]. This is supported by the fact that stiffness does not appear only in left ventricle [109]. Myocardial remodelling in HFpEF differs from the one observed in HFrEF, where remodelling is driven by loss of cardiomyocytes [109]. The new HFpEF paradigm proposes that comorbidities, plasma markers of inflammation and vascular hyperaemic responses should be included in diagnostic algorithms and intends to restore myocardial PKG activity with NO-donors, phosphodiesterase 5 inhibitors, and statins [109].

Despite the above data supporting the use of statins in HF, two large randomized trials, the Controlled Rosuvastatin Multinational Study in Heart failure (CORONA) trial [110] and the Gruppo Italiano per lo Studio della Sopravvivenza Nell' Insufficienza Cardiaca Heart Failure (GISSIHF) trial [111], which randomized patients to rosuvastatin 10 $\mathrm{mg} / \mathrm{d}$ or placebo, did not show improved survival in patients with HF. However, both studies mostly included patients with HFrEF $(100 \%$ in CORONA and $90 \%$ in GISSI-HF) $[110,111]$. In contrast to the latter studies, a prespecified post hoc analysis of the Treating to New Targets (TNT) study $(n=10,001)$, were patients with coronary heart disease (CHD) were randomized to either 10 or $80 \mathrm{mg} / \mathrm{d}$ of atorvastatin, showed a substantial reduction in hard endpoints in patients with pre-existing HF [112]. Intensive treatment with atorvastatin $80 \mathrm{mg} / \mathrm{d}$ reduced hospitalizations for $\mathrm{HF}$ compared with the $10 \mathrm{mg} / \mathrm{d}$ dose. This benefit was more pronounced in patients with a history of HF (hospitalization for HF, 17.3 vs $10.6 \%$ in the 10 - and $80 \mathrm{mg}$ arms, respectively; HR $0.59,95 \%$ CI 0.40 to $0.88, p=0.009)$. The mechanism accounting for this benefit was not a reduction in recurrent CVD events or a difference in BP [112]. Patients with symptoms of advanced HF or a known ejection fraction < $30 \%$ were excluded from TNT; however, a part of the study population had pre-existing HF ascertained by questionnaire at the time of enrolment. Given the limited information on type of HF and LV function, generalizations of these findings should be made with caution. Furthermore, HF outcomes in TNT did not examine LV function and therefore included both HFpEF and HFrEF patients [112]. However, regardless of the type of $\mathrm{HF}$, the $80 \mathrm{mg} / \mathrm{d}$ dose of atorvastatin reduced hospitalizations for $\mathrm{HF}$ by $41 \%$ over the $10 \mathrm{mg} / \mathrm{d}$; this is a very important finding and it is probably related to the statin and dose used.

We reported similar findings in the GREek Atorvastatin and Coronary-heart-disease Evaluation (GREACE) study [113]. Both in the original study and in a post hoc analysis, treatment with atorvastatin in 1,600 patients with CHD resulted in a reduction of $50 \%(95 \%$ CI $0.27-0.94, \mathrm{p}=0.021)$ in new or worsening cases of $\mathrm{HF}$ requiring hospitalization compared with usual care $[113,114]$. In GREACE, 63 of 800 patients treated with atorvastatin had HF at baseline. Among these patients, 10 were hospitalized for HF during the 3-year follow-up and showed a $2 \%$ increase in estimated glomerular filtration rate (eGFR) at 1 year compared with a $7.5 \%$ increase in those not hospitalized for HF $(p=0.002)$ [113]. Among the 800 patients receiving usual care, 55 had HF at baseline, and of those, 21 were hospitalized for HF during 3year follow-up. These patients showed a 5\% decrease in 
eGFR at 1 year compared with a $1 \%$ increase in those not hospitalized for HF $(p=0.001)$ [113]. Therefore, the reduced risk for hospitalization for HF appears to be partly mediated by the improvement of renal function related to atorvastatin treatment [115]. These results are supported by the TNT findings [116], according to which improvement in kidney function may contribute to the beneficial effects of high-dose atorvastatin on HF hospitalization [116]. These findings suggest that the effects of statins in HF depend on the compound and dose used. Indeed, lipophilic statins appear to result in better clinical outcomes than hydrophilic statins in terms of HF-related events [117].

\section{CONCLUSIONS}

HFpEF is a major and growing public health problem in the Western world, currently accounting for half of all patients with HF. HFpEF has a multifactorial aetiology involving several interconnected physiological systems. For example, increases in AS, as seen in HTN and aging, can impair LV diastole. Ideally, the treatment of HFpEF should relieve symptoms and increase survival. The classical treatment of HFrEF did not improve survival and could not substantially reduce symptoms in patients with HFpEF. Further research is required to determine how to better target haemodynamic and cellular pathophysiology of diastolic and non-diastolic mechanisms of disease in order to reduce the substantial burden of morbidity and mortality in HFpEF, which is reaching epidemic proportions. Several drugs are in the pipeline but they will not be commercially available for several years. The aggressive treatment of comorbidities of both AS and $\mathrm{HFpEF}$ are at the present time the only available choice for the relief of the disease burden. Thus, drugs that improve ventricular-vascular coupling by targeting both ventricular and vascular stiffness (stiff heart and stiff arteries) may be of benefit in treating $\mathrm{HFpEF}$, especially when combined with other drugs that target inflammation and cardiomyocyte stiffness. Treatment of anaemia, sleep disorders, CKD, NAFLD, atrial fibrillation, DM, and careful use of diuretics to reduce preload are effective to some degree. Statin treatment should also be implemented, regardless of lipid values, because it has been shown to substantially improve quality of life and survival in patients with HFpEF.

\section{CONFLICT OF INTEREST}

The author(s) confirm that this article content has no conflicts of interest.

\section{ACKNOWLEDGEMENT}

Declared none.

\section{REFERENCES}

[1] Redfield MM, Jacobsen SJ, Burnett JC, Mahoney DW, Bailey KR, Rodeheffer RJ. Burden of systolic and diastolic ventricular dysfunction in the community. Appreciating the scope of the heart failure epidemic. JAMA 2003; 289: 194-202 Owan TE, Hodge DO, Herges RM, Jacobsen SJ, Roger VL, Redfield MM. Trends in prevalence and outcome of heart failure with preserved ejection fraction. N Eng1 J Med 2006; 355: 251-9. tricular diastolic dysfunction in the community: Results from a

Doppler echocardiographic-based survey of a population sample. Eur Heart J 2003; 24: 320-8.

[4] Oghlakian GO, Sipahi I, Fang JC. Treatment of heart failure with preserved ejection fraction: have we been pursuing the wrong paradigm? Mayo Clin Proc 2011; 86: 531-9.

[5] Oishi Y, Miyoshi H, Iuchi A, Nagase N, Ara N, Oki T. Negative impact of cardiovascular risk factors on left atrial and left ventricular function related to aortic stiffness. Circ J 2013; 77: 1490-8.

[6] Borlaug BA, Lam CS, Roger VL, Rodeheffer RJ, Redfield MM. Contractility and ventricular systolic stiffening in hypertensive heart disease: Insights into the pathogenesis of heart failure with preserved ejection fraction. J Am Coll Cardiol 2009; 54: 410-8.

[7] Vlachopoulos C, Alexopoulos N, Stefanadis C. Aortic stiffness: prime time for integration into clinical practice? Hellenic J Cardiol 2010; 51: 385-90.

[8] Athyros VG, Reklou A, Lazaridis A, Mitsiou E, Karagiannis A Effect of metabolic risk factors clustering with or without arterial hypertension on arterial stiffness. A narrative review. Diseases 2013 [in press]

[9] Vlachopoulos C, Aznaouridis K, O'Rourke MF, et al. Prediction of cardiovascular events and all-cause mortality with central haemodynamics: A systematic review and meta-analysis. Eur Heart J 2010; 31: 1865-71.

[10] Sassalos K, Vlachopoulos C, Alexopoulos N, Gialernios T, Aznaouridis K, Stefanadis C. The acute and chronic effect of cigarette smoking on the elastic properties of the ascending aorta in healthy male subjects. Hellenic J Cardiol 2006; 47: 263-8.

[11] Cruickshank K, Riste L, Anderson SG, Wright JS, Dunn G, Gosling RG. Aortic pulse-wave velocity and its relationship to mortality in diabetes and glucose intolerance: an integrated index of vascular function? Circulation 2002; 106: 2085-90.

[12] Kawaguchi M, Hay I, Fetics B, Kass DA. Combined ventricular systolic and arterial stiffening in patients with heart failure and preserved ejection fraction: Implications for systolic and diastolic reserve limitations. Circulation 2003; 107: 714-20.

[13] Redfield MM, Jacobsen SJ, Borlaug BA, Rodeheffer RJ, Kass DA. Age- and gender-related ventricular-vascular stiffening: a community-based study. Circulation 2005; 112: 2254-62.

[14] Antonini-Canterin F, Carerj S, Di Bello V, et al. Research Group of the Italian Society of Cardiovascular Echography (SIEC). Arterial stiffness and ventricular stiffness: a couple of diseases or a coupling disease? A review from the cardiologist's point of view. Eur J Echocardiography 2009; 10: 36-43.

[15] Zouein FA, de Castro Brás LE, da Costa DV, Lindsey ML, Kurdi $\mathrm{M}$, Booz GW. Heart failure with preserved ejection fraction: emerging drug strategies. J Cardiovasc Pharmacol 2013; 62: 1321.

[16] Borlaug BA, Lam CS, Roger VL, Rodeheffer RJ, Redfield MM. Contractility and ventricular systolic stiffening in hypertensive heart disease: Insights into the pathogenesis of heart failure with preserved ejection fraction. J Am Coll Cardiol 2009; 54: 410-8.

[17] Lam CS, Roger VL, Rodeheffer RJ, et al. Cardiac structure and ventricular-vascular function in persons with heart failure and preserved ejection fraction from Olmsted County, Minnesota. Circulation 2007; 115: 1982-90.

[18] Seferovic PM, Stoerk S, Filippatos G, et al. Committee of National Heart Failure Societies or Working Groups of the Heart Failure Association of the European Society of Cardiology. Organization of heart failure management in European Society of Cardiology member countries: survey of the Heart Failure Association of the European Society of Cardiology in collaboration with the Heart Failure National Societies/Working Groups. Eur J Heart Fail 2013; 15: 947-59.

[19] Borlaug BA, Paulus WJ. Heart failure with preserved ejection fraction: pathophysiology, diagnosis, and treatment. Eur Heart J 2011; 32: 670-9.

[20] Yusuf S, Pfeffer MA, Swedberg K, et al. Effects of candesartan in patients with chronic heart failure and preserved left-ventricular ejection fraction: the CHARM-Preserved trial. Lancet 2003; 362: $777-81$.

[21] Cleland JG, Tendera M, Adamus J, Freemantle N, Polonski L, Taylor J. The Perindopril in Elderly People With Chronic Heart Failure (PEP-CHF) study. Eur Heart J 2006; 27: 2338-45.

[22] Schwartzenberg S, Redfield MM, From AM, Sorajja P, Nishimura RA, Borlaug BA. Effects of vasodilation in heart failure with preserved or reduced ejection fraction implications of distinct patho- 
physiologies on response to therapy. J Am Coll Cardiol 2012; 59: 442-51.

[23] Sherazi S, Zaręba W. Diastolic heart failure: predictors of mortality. Cardiol J 2011; 18: 222-32.

[24] Zile MR, Gaasch WH, Anand IS, et al. Mode of death in patients with heart failure and a preserved ejection fraction: Results from the Irbesartan in Heart Failure With Preserved Ejection Fraction Study (I-Preserve) trial. Circulation 2010; 121: 1393-405.

[25] Ather S, Chan W, Bozkurt B, et al. Impact of Noncardiac Comorbidities on Morbidity and Mortality in a Predominantly Male Population With Heart Failure and Preserved Versus Reduced Ejection Fraction. J Am Coll Cardiol 2012; 59: 998-1005.

[26] Hummel SL, Seymour EM, Brook RD, et al. Low-Sodium DASH Diet Improves Diastolic Function, Contractility, and VentriculoArterial Coupling in Hypertensive Heart Failure with Preserved Ejection Fraction. J Card Fail 2013 Aug 28 [Epub ahead of print]

[27] Athyros VG, Pagourelias ED, Gossios TD, Vasilikos VG. Treating heart failure with preserved ejection fraction related to arterial stiffness. Can we kill two birds with one stone? Curr Vasc Pharmacol 2013 [In press].

[28] Cleland JGF, Pellicori P. Defining diastolic heart failure and identifying effective therapies. JAMA 2013; 309: 825-6.

[29] Edelmann F, Wachter R, Schmidt AG, et al. Aldo-DHF Investigators. Effect of spironolactone on diastolic function and exercise capacity in patients with heart failure with preserved ejection fraction: the Aldo-DHF randomized controlled trial. JAMA 2013; 309: 781-91.

[30] Chantler PD, Lakatta EG, Najjar SS. Arterial-ventricular coupling: mechanistic insights into cardiovascular performance at rest and during exercise. J Appl Physiol 2008; 105: 1342-51.

[31] Redfield MM, Jacobsen SJ, Borlaug BA, Rodeheffer RJ, Kass DA. Age- and genderrelated ventricular-vascular stiffening: a community-based study. Circulation 2005; 112: 2254-62.

[32] Cohen-Solal A, Caviezel B, Laperche T, Gourgon R. Effects of aging on left ventricular-arterial coupling in man: assessment by means of arterial effective and left ventricular elastances. J Hum Hypertens 1996; 10: 111-6.

[33] Chantler PD, Melenovsky V, Schulman SP, et al. The sex-specific impact of systolic hypertension and systolic blood pressure on arterial-ventricular coupling at rest and during exercise. Am J Physiol Heart Circ Physiol 2008; 295: H145-H153.

[34] Lam CS, Shah AM, Borlaug BA, et al. Effect of antihypertensive therapy on ventricular-arterial mechanics, coupling, and efficiency. Eur Heart J 2013; 34: 676-83.

[35] Solomon SD, Janardhanan R, Verma A, et al. Valsartan In Diastolic Dysfunction (VALIDD) Investigators. Effect of angiotensin receptor blockade and antihypertensive drugs on diastolic function in patients with hypertension and diastolic dysfunction: a randomised trial. Lancet 2007; 369: 2079-87.

[36] Solomon SD, Verma A, Desai A, et al. Exforge Intensive Control of Hypertension to Evaluate Efficacy in Diastolic Dysfunction Investigators. Effect of intensive versus standard blood pressure lowering on diastolic function in patients with uncontrolled hypertension and diastolic dysfunction. Hypertension 2010; 55: 241-8.

[37] Scantlebury DC, Borlaug BA. Why are women more likely than men to develop heart failure with preserved ejection fraction? Curr Opin Cardiol 2011; 26: 562-8.

[38] Brouwers FP, de Boer RA, van der Harst P, et al. Incidence and epidemiology of new onset heart failure with preserved vs. reduced ejection fraction in a community-based cohort: 11-year follow-up of PREVEND. Eur Heart J 2013; 34: 1424-31.

[39] Becher PM, Lindner D, Miteva K, et al. Role of heart rate reduction in the prevention of experimental heart failure: comparison between If-channel blockade and beta-receptor blockade. Hypertension 2012; 59: 949-57.

[40] Reil JC, Hohl M, Reil GH, et al. Heart rate reduction by Ifinhibition improves vascular stiffness and left ventricular systolic and diastolic function in a mouse model of heart failure with preserved ejection fraction. Eur Heart J 2013; 34: 2839-49.

[41] Lovelock JD, Monasky MM, Jeong EM, et al. Ranolazine improves cardiac diastolic dysfunction through modulation of myofilament calcium sensitivity. Circ Res 2012; 110: 841-50.

[42] Jeong EM, Monasky MM, Gu L, et al. Tetrahydrobiopterin improves diastolic dysfunction by reversing changes in myofilament properties. J Mol Cell Cardiol 2013; 56: 44-54.
[43] Moens AL, Ketner EA, Takimoto E, et al. Bi-modal dosedependent cardiac response to tetrahydrobiopterin in pressureoverload induced hypertrophy and heart failure. J Mol Cell Cardiol 2011; 51: 564-9.

[44] Westermann D, Riad A, Richter U, et al. Enhancement of the endothelial NO synthase attenuates experimental diastolic heart failure. Basic Res Cardiol 2009; 104: 499-509.

[45] Tocchetti CG, Stanley BA, Murray CI, et al. Playing with cardiac 'redox switches': the 'HNO way' to modulate cardiac function. Antioxid Redox Signal 2011; 14: 1687-98.

[46] Gao WD, Murray CI, Tian Y, et al. Nitroxyl-mediated disulfide bond formation between cardiac myofilament cysteines enhances contractile function. Circ Res 2012; 111: 1002-11.

[47] Chiao YA, Ramirez TA, Zamilpa R, et al. Matrix metalloproteinase-9 deletion attenuates myocardial fibrosis and diastolic dysfunction in ageing mice. Cardiovasc Res 2012; 96: 444-5.

[48] Lauer-Fields JL, Whitehead JK, Li S, et al. Selective modulation of matrix metalloproteinase 9 (MMP-9) functions via exosite inhibition. J Biol Chem 2008; 283: 20087-95

[49] Baicu CF, Zile MR, Aurigemma GP, Gaasch WH. Left ventricular systolic performance, function, and contractility in patients with diastolic heart failure. Circulation 2005; 111:2306-12.

[50] Mir SA, Chatterjee A, Mitra A, et al. Inhibition of signal transducer and activator of transcription 3 (STAT3) attenuates interleukin-6 (IL-6)-induced collagen synthesis and resultant hypertrophy in rat heart. J Biol Chem 2012; 287: 2666-77.

[51] Willemsen S, Hartog JW, van Veldhuisen DJ, et al. The role of advanced glycation end-products and their receptor on outcome in heart failure patients with preserved and reduced ejection fraction. Am Heart J 2012; 164: 742-9. e3.

[52] Little WC, Zile MR, Kitzman DW, et al. The effect of alagebrium chloride (ALT-711), a novel glucose cross-link breaker, in the treatment of elderly patients with diastolic heart failure. J Card Fail 2005; 11: 191-5.

[53] Booz GW. Putting the brakes on cardiac hypertrophy: exploiting the NO-cGMP counterregulatory system. Hypertension 2005; 45 : 341-6.

[54] Solomon SD, Zile M, Pieske B, et al. Prospective comparison of ARNI with ARB on Management Of heart failUre with preserved ejectioN fracTion (PARAMOUNT) Investigators. The angiotensin receptor neprilysin inhibitor LCZ696 in heart failure with preserved ejection fraction: a phase 2 double-blind randomised controlled trial. Lancet 2012; 380: 1387-95.

[55] Wilson RM, De Silva DS, Sato K, et al. Effects of fixed-dose isosorbide dinitrate/hydralazine on diastolic function and exercise capacity in hypertension-induced diastolic heart failure. Hypertension 2009; 54: 583-90.

[56] Wojtczak-Soska K, Pietrucha T, Sakowicz A, et al. Soluble ST2 protein in chronic heart failure is independent of traditional factors. Arch Med Sci 2013; 9: 21-6.

[57] Bujak M, Frangogiannis NG. The role of IL-1 in the pathogenesis of heart disease. Arch Immunol Ther Exp (Warsz) 2009; 57: 16576.

[58] Sherazi S, Zaręba W. Diastolic heart failure: predictors of mortality. Cardiol J 2011; 18: 222-32.

[59] McMurray JJ, Adamopoulos S, Anker SD, et al; ESC Committee for Practice Guidelines. ESC Guidelines for the diagnosis and treatment of acute and chronic heart failure 2012: The Task Force for the Diagnosis and Treatment of Acute and Chronic Heart Failure 2012 of the European Society of Cardiology. Developed in collaboration with the Heart Failure Association (HFA) of the ESC. Eur Heart J 2012; 33: 1787-847.

[60] Triposkiadis FK, Skoularigis J. Prevalence and importance of comorbidities in patients with heart failure. Curr HeartFail Rep 2012; 9: 354-62.

[61] Lang CC, Mancini DM. Non-cardiac comorbidities in chronic heart failure. Heart 2007; 93: 665-71.

[62] Triposkiadis F, Starling RC, Boudoulas H, et al. The cardiorenal syndrome in heart failure: Cardiac? Renal? Syndrome? Hear Fail Rev 2012; 17: 355-66.

[63] Kaila K, Haykowsky MJ, Thompson RB, Paterson DI. Heart failure with preserved ejection fraction in the elderly: scope of the problem. Heart Fail Rev 2012; 17: 555-62.

[64] Laurent S, Boutouyrie P. Recent advances in arterial stiffness and wave reflection in human hypertension. Hypertension 2007; 49: 1202-6. 
[65] Cohen RS, Karlin P, Yushak M, Mancini D, Maurer MS. The effect of erythropoietin on exercise capacity, left ventricular remodeling, pressure-volume relationships, and quality of life in older patients with anemia and heart failure with preserved ejection fraction. Congest Heart Fail 2010; 16: 96-103.

[66] ALLHAT Officers and Coordinators for the ALLHAT Collaborative Research Group. The Antihypertensive and Lipid-Lowering Treatment to Prevent Heart Attack Trial. Major outcomes in highrisk hypertensive patients randomized to angiotensin-converting enzyme inhibitor or calcium channel blocker vs diuretic: The Antihypertensive and Lipid-Lowering Treatment to Prevent Heart Attack Trial (ALLHAT). JAMA 2002; 288: 2981-97.

[67] Beckett NS, Peters R, Fletcher AE, et al. HYVET Study Group. Treatment of hypertension in patients 80 years of age or older. $\mathrm{N}$ Engl J Med 2008; 358:1887-98.

[68] Athyros VG, Mikhailidis DP, Papageorgiou AA, et al. The effect of statins versus untreated dyslipidaemia on renal function in patients with coronary heart disease. A subgroup analysis of the Greek atorvastatin and coronary heart disease evaluation (GREACE) study. J Clin Pathol 2004; 57: 728-34.

[69] Athyros VG, Tziomalos K, Gossios TD, et al. Safety and efficacy of long-term statin treatment for cardiovascular events in patients with coronary heart disease and abnormal liver tests in the Greek Atorvastatin and Coronary Heart Disease Evaluation (GREACE) study: a post-hoc analysis. Lancet 2010; 376: 1916-22.

[70] Athyros VG, Mikhailidis DP, Didangelos TP, et al. Effect of multifactorial treatment on non-alcoholic fatty liver disease in metabolic syndrome: a randomised study. Curr Med Res Opin 2006; 22: 87383.

[71] Athyros VG, Ganotakis E, Kolovou GD, et al. Assessing The Treatment Effect in Metabolic Syndrome Without Perceptible Diabetes (ATTEMPT) Collaborative. Assessing the treatment effect in metabolic syndrome without perceptible diabetes (ATTEMPT): a prospective-randomized study in middle aged men and women. Curr Vasc Pharmacol 2011; 9: 647-57.

[72] Athyros VG, Giouleme O, Ganotakis ES, et al. Safety and impact on cardiovascular events of long-term multifactorial treatment in patients with metabolic syndrome and abnormal liver function tests: a post hoc analysis of the randomised ATTEMPT study. Arch Med Sci 2011; 7: 796-805.

[73] Kargiotis K, Katsiki N, Athyros VG, et al. Effect of rosuvastatin on non-alcoholic steatohepatitis in patients with metabolic syndrome and hypercholesterolaemia. A preliminary report. Curr Vasc Pharmacol 2013 [in press]

[74]. Athyros VG, Katsiki N, Karagiannis A, Mikhailidis DP. Statins and nonalcoholic fatty liver disease: a bright future? Expert Opin Investig Drugs 2013; 22: 1089-93

[75] Targher G, Mantovani A, Pichiri I, et al. Non-alcoholic fatty liver disease is associated with an increased prevalence of atrial fibrillation in hospitalized patients with type 2 diabetes. Clin Sci (Lond) 2013; 125: 301-9.

[76] Wang ZG, Chen BW, Lü NQ, Cheng YM, Dang AM. Relationships between use of statins and arterial stiffness in normotensive and hypertensive patients with coronary artery disease. Chin Med J (Engl) 2013; 126: 3087-92.

[77] Bitter T, Westerheide N, Faber L, et al. Adaptive servoventilation in diastolic heart failure and Cheyne-Stokes respiration. Eur Respir J 2010; 36: 385-92.

[78] Teupe C, Rosak C. Diabetic cardiomyopathy and diastolic heart failure - difficulties with relaxation. Diabetes Res Clin Pract 2012; 97: 185-94.

[79] Masoudi FA, Inzucchi SE, Wang Y, Havranek EP, Foody JM, Krumholz HM. Thiazolidinediones, metformin, and outcomes in older patients with diabetes and heart failure: an observational study. Circulation 2005; 111: 583-90

[80] Naka KK, Pappas K, Papathanassiou K, et al. Lack of effects of pioglitazone on cardiac function in patients with type 2 diabetes and evidence of left ventricular diastolic dysfunction: a tissue doppler imaging study. Cardiovasc Diabetol 2010; 9: 57-65.

[81] Eurich DT, Majumdar SR, McAlister FA, Tsuyuki RT, Johnson JA. Improved clinical outcomes associated with metformin in patients with diabetes and heart failure. Diabetes Care 2005; 28: 2345-51.

[82] Benes J, Kazdova L, Drahota Z, et al. Effect of metformin therapy on cardiac function and survival in a volume-overload model of heart failure in rats. Clin Sci (Lond) 2011; 121: 29-41.
[83] Liu Q, Anderson C, Broyde A, et al. Glucagon-like peptide-1 and the exenatide analogue AC3174 improve cardiac function, cardiac remodeling, and survival in rats with chronic heart failure. Cardiovasc Diabetol 2010; 9: 76-89.

[84] Chen CH, Nakayama M, Nevo E, Fetics BJ, Maughan WL, Kass DA. Coupled systolic- ventricular and vascular stiffening with age: implications for pressure regulation and cardiac reserve in the elderly. J Am Coll Cardiol 1998; 32: 1221-7.

[85] Daemen J. Diastolic dysfunction and arterial stiffness: the chicken or the egg. Neth Heart J 2013; 21:219-21.

[86] Athyros VG, Kakafika AI, Tziomalos K, Karagiannis A, Mikhailidis DP. Pleiotropic effects of statins-clinical evidence. Curr Pharm Des 2009; 15: 479-89.

[87] Athyros VG, Katsiki N, Karagiannis A. Treating Heart Failure With Preserved Ejection Fraction: Statins Could Make the Difference. Angiology 2013 [In press] DOI: 10.1177/0003319713507629

[88] Wang JQ, Wu GR, Wang Z, Dai XP, Li XR. Long-term Clinical Outcomes of Statin Use for Chronic Heart Failure: A Meta-analysis of 15 Prospective Studies. Heart Lung Circ 2013 Aug 17. [Epub ahead of print] doi: 10.1016/j.hlc.2013.07.012.

[89] Fukuta H, Sane DC, Brucks S, Little WC. Statin therapy may be associated with lower mortality in patients with diastolic heart failure: a preliminary report. Circulation 2005; 112: 357-63.

[90] Foody JM, Shah R, Galusha D, Masoudi FA, Havranek EP, Krumholz HM. Statins and mortality among elderly patients hospitalized with heart failure. Circulation 2006; 113: 1086-92.

[91] Tehrani F, Morrissey R, Phan A, Chien C, Schwarz ER. Statin therapy in patients with diastolic heart failure. Clin Cardiol 2010; 33: E1-5.

[92] Roik M, Starczewska MH, Huczek Z, Kochanowski J, Opolski G. Statin therapy and mortality among patients hospitalized with heart failure and preserved left ventricular function-a preliminary report. Acta Cardiol 2008; 63: 683-92.

[93] Kanaki AI, Sarafidis PA, Georgianos PI, et al. Effects of low-dose atorvastatin on arterial stiffness and central aortic pressure augmentation in patients with hypertension and hypercholesterolemia. Am J Hypertens 2013; 26: 608-16.

[94] Sadat U, Howarth SP, Usman A, et al. Effect of low-and high-dose atorvastatin on carotid artery distensibility using carotid magnetic resonance imaging -a post-hoc sub group analysis of ATHEROMA (Atorvastatin Therapy: Effects On Reduction Of Macrophage Activity) Study. J Atheroscler Thromb 2013; 20: 46-56.

[95] Matsuo T, Iwade K, Hirata N, et al. Improvement of arterial stiffness by the antioxidant and anti-inflammatory effects of short-term statin therapy in patients with hypercholesterolemia. Heart Vessels 2005; 20: 8-12.

[96] Wang F, Ye P, Luo L, et al. Association of serum lipids with arterial stiffness in a population-based study in Beijing. Eur J Clin Invest 2011; 41: 929-36.

[97] Hongo M, Kumazaki S, Izawa A, et al. Low-dose rosuvastatin improves arterial stiffness in high-risk Japanese patients with dyslipdemia in a primary prevention group. Circ J 2011; 75: 26607.

[98] Hongo M, Tsutsui, H, Mawatari E, et al. Fluvastatin improves arterial stiffness in patients with coronary artery disease and hyperlipidemia: a 5-year follow-up study. Circ J 2008; 72: 722-8.

[99] Kontopoulos AG, Athyros VG, Pehlivanidis AN, Demitriadis DS, Papageorgiou AA, Boudoulas H. Long-term treatment effect of atorvastatin on aortic stiffness in hypercholesterolaemic patients. Curr Med Res Opin 2003; 19: 22-7.

[100] Igase M, Kohara K, Tabara Y, et al. Low-dose rosuvastatin improves the functional and morphological markers of atherosclerosis in asymptomatic postmenopausal women with dyslipidemia. Menopause 2012; 19: 1294-9.

[101] Fassett RG, Robertson IK, Ball MJ, Geraghty DP, Sharman JE, Coombes JS. Effects of atorvastatin on arterial stiffness in chronic kidney disease: a randomised controlled trial. J Atheroscler Thromb 2010; 17; 235-41.

[102] Orr JS, Dengo AL, Rivero JM, Davy KP. Arterial destiffening with atorvastatin in overweight and obese middle-aged and older adults. Hypertension 2009; 54: 763-8.

[103] Mukherjee S, Mukhopadhyay P, Pandit K, Chowdhury S. Atorvastatin improves arterial stiffness in normotensive normolipidaemic persons with type 2 diabetes. J Indian Med Assoc 2008; 106: 7169. 
[104] Haller MJ, Stein JM, Shuster JJ, et al. Pediatric Atorvastatin in Diabetes Trial (PADIT): a pilot study to determine the effect of atorvastatin on arterial stiffness and endothelial function in children with type 1 diabetes mellitus. J Pediatr Endocrinol Metab 2009; 22: 65-8.

[105] Lunder M, Janić M, Habjan S, Sabovič M. Subtherapeutic, lowdose fluvastatin improves functional and morphological arterial wall properties in apparently healthy, middle-aged males-a pilot study. Atherosclerosis 2011;215: 446-51.

[106] Tam LS, Li EK, Shang Q, et al. Effects of rosuvastatin on subclinical atherosclerosis and arterial stiffness in rheumatoid arthritis: a randomized controlled pilot trial. Scand J Rheumatol 2011; 40: 411-21.

[107] Wang J, Xu J, Zhou C, et al. Improvement of arterial stiffness by reducing oxidative stress damage in elderly hypertensive patients after 6 months of atorvastatin therapy. J Clin Hypertens (Greenwich) 2012; 14: 245-9.

[108] Toyama K, Sugiyama S, Oka H, et al. Combination treatment of rosuvastatin or atorvastatin, with regular exercise improves arterial wall stiffness in patients with coronary artery disease. PLoS One 2012; 7: e41369-76.

[109] Jondeau G, Arnoult F, Caligiuri G, et al. Practical management of heart failure with preserved ejection fraction. A modest proposal. Arch Cardiovasc Dis 2013; 106: 345-8.

[110] Kjekshus J, Apetrei E, Barrios V, et al. CORONA Group Rosuvastatin in older patients with systolic heart failure. $\mathrm{N}$ Engl $\mathrm{J}$ Med 2007; 357: 2248-61.
[111] Tavazzi L, Maggioni AP, Marchioli R, et al. Gissi-HF Investigators Effect of rosuvastatin in patients with chronic heart failure (the GISSI-HF trial): a randomised, double-blind, placebo-controlled trial. Lancet 2008; 372: 1231-9.

[112] Khush KK, Waters DD, Bittner V, et al. Effect of high-dose atorvastatin on hospitalizations for heart failure: subgroup analysis of the Treating to New Targets (TNT) study. Circulation 2007; 115: 576-83.

[113] Athyros VG, Papageorgiou AA, Mercouris BR, et al. Treatment with atorvastatin to the National Cholesterol Educational Program goal versus 'usual' care in secondary coronary heart disease prevention The GREek Atorvastatin and Coronary-heart-disease Evaluation (GREACE) study. Curr Med Res Opin 2002; 18: 220-8.

[114] Athyros VG, Karagiannis A, Mikhailidis DP. Statins and heart failure. J Am Coll Cardiol 2010; 55: 1644-5.

[115] Athyros VG, Karagiannis A, Katsiki N, Mikhailidis DP. Relation of improvement in glomerular filtration rate with atorvastatin to reductions in heart failure morbidity. Am J Cardiol 2012; 110: 763.

[116] Jennifer E. Ho, David D. Waters, et al. TNT Investigators. Relation of improvement in estimated glomerular filtration rate with atorvastatin to reductions in hospitalizations for heart failure (from the Treating to New Targets [TNT] Study). Am J Cardiol 2012; 109: 1761-6.

[117] Bonsu KO, Kadirvelu A, Reidpath DD. Statins in heart failure: do we need another trial? Vasc Health Risk Manag 2013; 9: 303-19.

(C) Athyros et al.; Licensee Bentham Open.

This is an open access article licensed under the terms of the Creative Commons Attribution Non-Commercial License (http://creativecommons.org/licenses/by-nc/3.0/) which permits unrestricted, non-commercial use, distribution and reproduction in any medium, provided the work is properly cited. 